\title{
THORACOLUMBAR SYMPATHECTOMY IN HYPERTENSION
}

\author{
By W. E. PARKES \\ From the Royal Victoria Hospital, Belfast
}

Received July 30, 1957

The average survival time of patients in the malignant phase of hypertension is short-eight months according to Keith et al. (1928). There have been many reports of the effects of bilateral thoracolumbar sympathectomy on the mortality rate in.this disease. Woods and Peet (1941) recorded a survival rate of 33 per cent five years after operation and Peet and Isberg (1946) a rate of 19 per cent after five to eleven years. Evelyn et al. (1949) noted that in twelve of their patients papillœdema disappeared but there was no significant fall in blood pressure. In England, Morrissey et al. (1953) have had encouraging results in the treatment of severe hypertension, but Pickering (1955) recorded an adequate fall in blood pressure in only 18 per cent of 142 patients two years after operation.

Bilateral thoracolumbar sympathectomy is a major surgical procedure and may be followed by troublesome complications such as causalgia and postural hypotension. Many centres have, therefore, abandoned the operation in favour of "medical sympathectomy" by ganglion-blocking drugs. Unfortunately, not all the patients suffering from severe diastolic hypertension respond adequately to these drugs. The recently introduced mecamylamine is said to be more effective than the other ganglion-blocking agents, but it has a potent vagal blocking effect. In view of the difficulty in connection with ganglion-blocking drugs, it was thought that a review of the results of thoracolumbar sympathectomy in this hospital would be of value.

Before operation all patients had undergone a full clinical examination, followed by examination of the urine, specific gravity range test, blood urea estimation, intravenous pyelogram, and by cardioscopy, electrocardiogram, and a sedation test. A few had slight albuminuria, but none had significant impairment of renal function or evidence of cardiac failure. Only one was over the age of 50. The positive indications were a persistent diastolic blood pressure above $130 \mathrm{~mm}$. $\mathrm{Hg}$ or intractable headaches and rapid deterioration of vision. The headaches were intense in 27 of the 31 patients.

\section{RESULTS}

This report deals with 31 patients who attended for review 6 months to 8 years after thoracolumbar sympathectomy of the Smithwick type with splanchnicectomy and removal of the sympathetic chain from at least T8 to L2 or 3: in several instances the sympathetic chain was removed up to T4. Six patients had malignant hypertension.

The data are sumarized in Table I. The initial blood pressure refers to the lowest reading before therapy was started, and in most patients this was obtained after a few days in hospital. The basal pressure was the lowest obtained during the sodium amytal sedation test. A significant fall in blood pressure was regarded as one over $30 \mathrm{~mm}$. systolic and over $20 \mathrm{~mm}$. $\mathrm{Hg}$ diastolic. This occurred in approximately 32 per cent of the series over a period of 6 months to 8 years.

The average blood urea before operation was $31.2 \mathrm{mg}$. per $100 \mathrm{ml}$. The last assessment after operation showed a rise in the blood urea in 5 patients, the highest figure being $51 \mathrm{mg}$. per $100 \mathrm{ml}$.

The electrocardiographic changes were much improved in 8 patients, and an example is shown in Fig. 1. The left ventricular enlargement was appreciably reduced in 10 patients. 
TABLE 1

Results of ThORACOlumbar SyMPathectomy Operations

\begin{tabular}{|c|c|c|c|c|c|c|c|c|}
\hline \multirow{3}{*}{ No. } & \multirow{3}{*}{$\begin{array}{c}\text { Lowest } \\
\text { blood } \\
\text { pressure } \\
\text { before therapy }\end{array}$} & \multirow{3}{*}{ Sex } & \multirow{3}{*}{ Age } & \multirow{3}{*}{$\begin{array}{l}\text { Lowest } \\
\text { blood } \\
\text { pressure with } \\
\text { sodium amytal }\end{array}$} & \multicolumn{4}{|c|}{ Post-operative assessment } \\
\hline & & & & & \multirow{2}{*}{$\begin{array}{l}\text { No. of } \\
\text { months after } \\
\text { operation }\end{array}$} & \multicolumn{3}{|c|}{ Blood pressure } \\
\hline & & & & & & Recumbent & Standing & $\begin{array}{c}\text { On oral } \\
\text { reserpine \& } \\
\text { hydrallazine }\end{array}$ \\
\hline 1 & $260+/ 180$ & $\mathrm{~F}$ & 44 & $210 / 140$ & 37 & $260 / 155$ & $230 / 150$ & $170 / 120$ \\
\hline 2 & $240 / 125$ & $\mathrm{~F}$ & 45 & $230 / 110$ & 22 & $230 / 130$ & $160 / 115$ & $175 / 100$ \\
\hline 3 & $190 / 130$ & M & 40 & $180 / 130$ & 28 & $180 / 110$ & $160 / 115$ & - \\
\hline 4 & $230 / 125$ & $\mathrm{~F}$ & 46 & $230 / 125$ & 7 & $180 / 105$ & - & - \\
\hline $5^{*}$ & $205 / 135$ & $\mathrm{~F}$ & 38 & $170 / 115$ & 58 & $170 / 110$ & $140 / 105$ & - \\
\hline $6^{*}$ & $200 / 100$ & $\mathrm{~F}$ & 39 & $190 / 105$ & 20 & $220 / 110$ & $190 / 110$ & - \\
\hline 7 & $230 / 150$ & $\mathrm{M}$ & 38 & $210 / 125$ & 36 & $125 / 95$ & $130 / 100$ & - \\
\hline $8^{*}$ & $235 / 130$ & $\mathrm{~F}$ & 45 & $230 / 130$ & 44 & $165 / 100$ & $155 / 105$ & - \\
\hline 9 & $220 / 130$ & $\mathrm{~F}$ & 44 & $220 / 125$ & 70 & $220 / 135$ & $220 / 135$ & $170 / 100$ \\
\hline 10 & $220 / 140$ & $\mathrm{~F}$ & 33 & $220 / 140$ & 47 & $155 / 100$ & $140 / 105$ & - \\
\hline 11 & $260+/ 160$ & $\mathrm{~F}$ & 42 & $240 / 150$ & 52 & $190 / 135$ & $190 / 140$ & $190 / 105$ \\
\hline 12 & $250 / 135$ & $M$ & 55 & $200 / 125$ & 33 & $220 / 170$ & $175 / 140$ & - \\
\hline 13 & $260 / 140$ & $\mathbf{M}$ & 43 & $195 / 125$ & 62 & $190 / 110$ & $169 / 110$ & - \\
\hline 14 & $180 / 120$ & $\mathrm{~F}$ & 42 & $180 / 120$ & 56 & $160 / 95$ & $150 / 100$ & - \\
\hline 15 & $240 / 135$ & $\mathrm{~F}$ & 31 & $190 / 125$ & 45 & $170 / 100$ & $200 / 110$ & - \\
\hline 16 & $210 / 120$ & $\mathrm{~F}$ & 46 & $205 / 110$ & 21 & $160 / 100$ & $150 / 100$ & - \\
\hline 17 & $265 / 160$ & $\mathrm{~F}$ & 55 & $195 / 105$ & 13 & $200 / 95$ & $200 / 100$ & - \\
\hline 18 & - & $\mathrm{F}$ & 39 & $230 / 130$ & 47 & $180 / 105$ & $180 / 125$ & - \\
\hline 19 & $195 / 110$ & $\mathrm{~F}$ & 45 & $190 / 110$ & 102 & $230 / 130$ & $170 / 115$ & - \\
\hline 20 & $240 / 175$ & $M$ & 34 & $210 / 140$ & 26 & $215 / 130$ & $180 / 130$ & $120 / 90$ \\
\hline 21 & $260 / 180$ & $\mathbf{M}$ & 48 & $220 / 140$ & 47 & $220 / 135$ & $165 / 120$ & - \\
\hline 22 & $220 / 150$ & $\mathrm{~F}$ & 43 & $180 / 140$ & 17 & $170 / 110$ & & - \\
\hline 23 & $210 / 150$ & $M$ & 21 & $220 / 140$ & 6 & $220 / 150$ & $190 / 145$ & - \\
\hline 24 & - & M & 42 & $245 / 135$ & 59 & $140 / 100$ & $95 / 65$ & - \\
\hline 25 & $180 / 150$ & M & 29 & $170 / 125$ & 11 & $150 / 100$ & $135 / 100$ & - \\
\hline 26 & $230 / 130$ & M & 50 & $215 / 115$ & 6 & $210 / 140$ & $195 / 140$ & $180 / 110$ \\
\hline 27 & $240 / 165$ & $\mathrm{~F}$ & 20 & $220 / 140$ & 16 & $155 / 130$ & $165 / 140$ & $160 / 90$ \\
\hline 28 & $240 / 160$ & $\mathrm{~F}$ & 30 & $200 / 140$ & 14 & $250 / 160$ & $220 / 155$ & 10070 \\
\hline 29 & $260 / 140$ & $\mathrm{~F}$ & 46 & $220 / 110$ & 15 & $260 / 130$ & $250 / 130$ & $190 / 105$ \\
\hline 30 & - & $\mathrm{F}$ & 48 & $235 / 140$ & 72 & $165 / 100$ & $175 / 115$ & - \\
\hline 31 & $250 / 150$ & M & 25 & $250 / 145$ & 19 & $170 / 110$ & $150 / 110$ & - \\
\hline
\end{tabular}

* Patients who had first stage sympathectomy only.

After operation symptoms included exertional dyspnœa in 9 patients, residual headaches in 4, vertigo in 1, angina pectoris in 2, and a variable degree of postural hypotension is several cases. All patients who had previously complained of intense headaches felt that the operations had been well worth while.

\section{Discussion}

The effectiveness of thoracolumbar sympathectomy has been widely debated. Platt and Stanbury (1950) say "sympathectomy may be justifiable as a symptomatic measure for the relief of crippling headaches; but in a few patients relief may be bought at the price of new symptoms ... Some have exchanged severe headaches for severe exertional tachycardia and fatiguability". This is an extreme view, although the criticism is quite justifiable and was noted in the above series. The attitude of Rosenheim (1954) and Wells (1956) is more acceptable. They feel that the pendulum has swung too far away from operation and that there will probably be a continued and perhaps increasing demand for it in carefully selected cases.

As Fishberg (1954) points out, there is no evidence that sympathectomy is other than the production of one physiological derangement to counteract another. The dilatation of the splanchnic vessels 


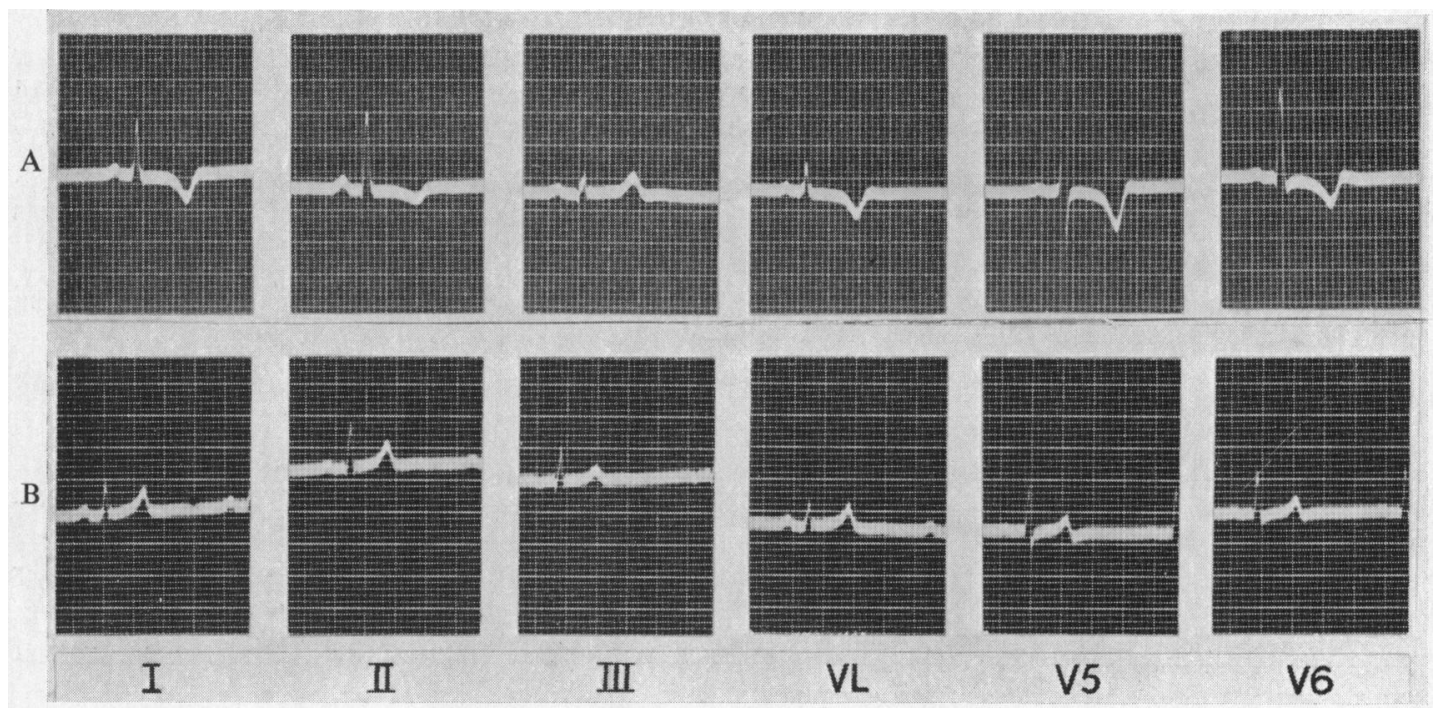

FIG. 1.-Electrocardiogram (A) before treatment (4/4/55), and (B) eight months afterwards (7/12/55), showing improvement in the $\mathrm{T}$ waves.

plays an important part in the hypotensive effect of sympathectomy. This may last for months or years but the diminution of peripheral resistance produced by sympathectomy may diminish as time goes by. Nevertheless the average survival time of patients who have had sympathectomy operations is much greater than could be expected without operation. Smithwick (1951) found that the mortality in 77 cases of malignant hypertension was 56 per cent, 5 to 12 years after operation, whereas in 174 medically treated nearly all had died.

There are several common post-operative complications. Following the second stage operation there is often profound hypotension: in one of the present series a nor-adrenaline intravenous drip had to be maintained for over 24 hours. Later, postural hypotension may be troublesome, but may be controlled by a firm abdominal binder. Pain due to cutting of the intercostal nerves at operation may require intercostal block.

There are two other complications that were not encountered in the present series. First, Blegan and Kintner (1947) report massive hæmorrhage from a peptic ulcer following a sympathectomy operation: one might expect this, as sympathectomy is the converse of vagotomy. Secondly, impotence has occurred in some young men, though in women sexual function does not seem to be disturbed.

The indications for thoracolumbar sympathectomy have varied over the years. At present it is agreed that hypotensive drugs should always be tried first. If these fail, the main indication is intractable headache with a persistently raised diastolic blood pressure. Secondly, if there is gross hypertensive retinopathy, in spite of medical treatment, the operation is indicated, as the vision can be much improved even if there is no subsequent fall in blood pressure.

Formerly the sodium amytal sedation test was widely used. If the blood pressure fell satisfactorily it was assumed that the patient would respond well to sympathectomy. In practice, no such correlation was found and the test has been abandoned.

Many contraindications to the operation have been suggested. It is seldom advised if the patient is over 50 years of age. It should never be advocated in the presence of significant impairment of renal function. Chavez and Mendez (1949) have described improvement in patients who were in cardiac failure before operation. Certainly gallop rhythm that persists despite bed rest, and the need for sodium restriction, digitalization, and mercurial diuretics may disappear after sympathectomy (Fishberg, 1954). 
The final column in Table I, shows that in many of the patients who did not have a satisfactory fall in blood pressure after operation, this was obtained by oral reserpine and hydrallazine. Schroeder (1952) also found out that patients were more sensitive to hydrallazine following unsuccessful thoracolumbar sympathectomy and Grimson et al. (1952) note that patients previously treated by sympathectomy usually derive a good fall of blood pressure from small doses of hypotensive drugs. Reserpine and hydrallazine act centrally and, when used with care, cause less troublesome side-effects than the more potent autonomic ganglion blocking drugs.

The majority of sympathectomy operations described in this report were undertaken before the introduction of the recent hypotensive drugs. It will be of interest to determine whether patients who fail to respond to reserpine and hydrallazine before sympathectomy do so after the operation.

\section{SUMMARY}

The results of thoracolumbar sympathectomy performed for severe hypertension have been reviewed.

Of 31 patients assessed at intervals varying from 6 months to 8 years after the operation 32 per cent showed a satisfactory fall in diastolic blood pressure. Many of those who failed to show a significant fall in blood pressure after this operation responded to combined oral reserpine and hydrallazine therapy.

Most of the patients were under the care of Dr. J. F. Pantridge who suggests this investigation. My thanks are also due to the late Mr. C. A. Calvert, who performed most of the operations and to Mr. A. R. Taylor and Mr. J. A. W. Bingham, who operated on the other patients.

\section{REFERENCES}

Blegan, H. M., and Kinter, A. R. (1947). J. Amer. med. Ass., 133, 1207.

Chavez, I., and Mendez, L. (1949). Amer Heart J., 37, 523.

Evelyn, K. A., Alexander, F., and Cooper, S. R. (1949). J. Amer. med. Ass., 149, 592.

Fishberg, A. M. (1954). Hypertension and Nephritis. Baillière, Tindall and Cox, London.

Grimson, K. S., Orgain, E. S., Rowe, C. R., and Sieber, H. A. (1952). J. Amer. med. Ass., 149, 215.

Keith, N. M., Wagener, H. P., and Kernohan, J. W. (1928). Arch. intern. Med., 41, 141.

Morrissey, D. M., Brookes, V. S., and Cooke, W. T. (1953). Lancet, 1, 403.

Peet, M. M., and Isberg, E. M. (1946). J. Amer. med. Ass., 130, 467.

Pickering, G. W. (1955). High Blood Pressure. J. and A. Churchill, London.

Platt, R., and Stanbury, S. W. (1950). Lancet, 1, 651.

Rosenheim, M. X. (1954). Brit. med. J., $2,1181$.

Schroeder, H. A. (1952). J. Lab. clin. Med., 38, 949.

Smithwick, R. H. (1951). J. Amer. med. Ass., 147, 1611.

Wells, C. (1956) Scot. med. J., 14, 245.

Woods, W. W., and Peet, M. M. (1941). J. Amer. med. Ass., 117, 1508. 